\title{
Moisture behavior calculation of single-layer enclosing structure by means of discrete- continuous method
}

\author{
Vladimir Gagarin ${ }^{1,}$, Vadim Akhmetov ${ }^{1}$, and Kirill Zubarev ${ }^{1, *}$ \\ ${ }^{1}$ Moscow State University of Civil Engineering, Yaroslavskoe shosse, 26, Moscow, 129337, Russia
}

\begin{abstract}
The paper proposes mathematical model for unsteady-state moisture behaviour calculation of single-layer enclosing structures by means of moisture potential and discrete-continuous method. A formula for moisture potential value calculation for single-layer enclosing structure in any enclosing structure section, at any moment of time, under continuous control for temperature distribution, has been derived. Moisture transfer between the enclosing structure and ambient air is taken into account by means of third-kind boundary conditions. Temperature distribution is taken as constant during a month. The proposed method allows for moisture potential determination according to the proposed formula for every month. Calculation results obtained by the proposed method, well-known unsteady-state method and engineering method developed by V.G. Gagarin and V.V.Kozlov have been compared for single-layer enclosing structure made of aerated concrete. It was shown that average value calculation results disagreement does not exceed $7 \%$ for the proposed method and unsteady-state method. However, the proposed approach allows for moisture distribution determination using analytical expression, which is convenient for use in engineering practice.
\end{abstract}

\section{Introduction}

Moisture behavior researches are actual at present. Moisture in construction material has an effect on thermal properties of building thermal protection shell [1-4]. Errors in moisture behavior assessment can result in reduction of enclosing structure durability [5-8]. Thus one of the most important research problem is to develop calculation methods for enclosing structure moisture condition [9-12] and further theoretical results checkup by means of field studies $[13,14]$ and laboratory experiments $[15,16]$.

Gagarin's mathematical model [17] is well-known. Moisture flow is represented as a sum of liquid and vapor moisture flows within this model:

$$
g_{\text {tot }}=g_{v}+g_{L} \text {. }
$$

where $g_{\text {tot }}$ - total moisture flow, $\mathrm{kg} /\left(\mathrm{m}^{2} \cdot s\right), g_{v}$ - vapour moisture flow, $\mathrm{kg} /\left(\mathrm{m}^{2} \cdot \mathrm{s}\right), g_{L}$ - liquid moisture flow, $\mathrm{kg} /\left(\mathrm{m}^{2} \cdot s\right)$.

\footnotetext{
*Corresponding author: zubarevkirill93@mail.ru
} 
Temperature distribution is described by differential thermal conductivity equation:

$$
\frac{\partial t}{\partial \tau}=a \cdot \frac{\partial^{2} t}{\partial x^{2}} \text {. }
$$

where $t$ - temperature, ${ }^{\circ} \mathrm{C} ; \tau$ - time, $s ; x$ - coordinate, $m ; a$ - material temperature conductivity coefficient, $\mathrm{m}^{2} / \mathrm{s}$.

Moisture distribution is described by differential moisture transfer equation:

$$
\frac{\partial F}{\partial \tau}=\frac{\partial}{\partial x}\left(\left(\frac{1}{\mu} \beta+\frac{\partial \varphi}{\partial w} E_{t}\right) \cdot \frac{\mu}{\gamma_{0}} \cdot \frac{\partial F}{\partial x}\right) .
$$

where $F$ - moisture potential, $\mathrm{Pa} ; \beta$ - moisture conductivity coefficient, $\mathrm{kg} /(\mathrm{m} \cdot \mathrm{s} \cdot \mathrm{kg} / \mathrm{kg})$; $\mu$ - vapor permeability coefficient $\mathrm{kg} /(\mathrm{m} \cdot \mathrm{s} \cdot \mathrm{Pa}) ; \gamma_{0}$ - enclosing structure dry material density, $\mathrm{kg} / \mathrm{m}^{3} ; E_{t}$ - maximum water vapor pressure, Pa.

Equation (3) is used with third-kind boundary conditions described below.

Moisture potential $F$ takes into account both liquid and vapor moisture flow with the ratio:

$$
F=E_{t} \cdot \varphi+\frac{1}{\mu} \int_{0}^{w} \beta(\zeta) d \zeta .
$$

Mathematical model in hand allows for enclosing structure moisture behavior determination to high precision, however it requires numerical method, which makes it difficult to use this model in construction practice.

Kozlov's method based on research of steady-state distribution of moisture potential and temperature is easier to use in engineering practice.

In this case temperature distribution is taken as

And moisture distribution as

$$
\frac{\partial^{2} t}{\partial x^{2}}=0
$$

$$
\frac{\partial^{2} F}{\partial x^{2}}=0
$$

Expressions (5) and (6) allows for analytical calculation of enclosing structure moisture behavior, but this calculation is much less accurate as compared to (2) and (3) equations calculation.

\section{The problems}

The aim of the research is to develop engineering method for unsteady-state moisture behavior calculation of the enclosing structure, which allows moisture determination in any enclosing structure section, at any moment of time, under continuous control for temperature distribution, taking into account moisture transfer between enclosing structure and air, using discrete-continuous approach and third-kind boundary conditions.

\section{Materials and Methods}

Let's introduce moisture transfer mathematical model with averaging of all nonlinear terms of equation (3), responsible for moisture distribution, except for maximum water vapor tension, which is responsible for temperature distribution: 


$$
\frac{\partial F}{\partial \tau}=\kappa \frac{\partial}{\partial x}\left(E_{t} \frac{\partial F}{\partial x}\right)
$$

where $\kappa$ - average coefficient, $m^{2} /(s \cdot P a)$.

$$
\kappa=\frac{\mu}{\gamma_{0} \cdot \xi_{F 0}} .
$$

where $\xi_{F 0}$ - material relative potential capacity coefficient, $\mathrm{kg} / \mathrm{kg}$.

The product of average coefficient $\kappa$ and maximum water vapor pressure $E_{t}$ makes physical sense of potential conductivity. It is supposed to use steady-state temperature distribution by expression (5) during assessment month to represent maximum water vapor tension as a linear member. In this case for the assessment month the equation (7) is a differential parabolic equation with constant coefficients. Spatial-time domain is given at [fig. 1].

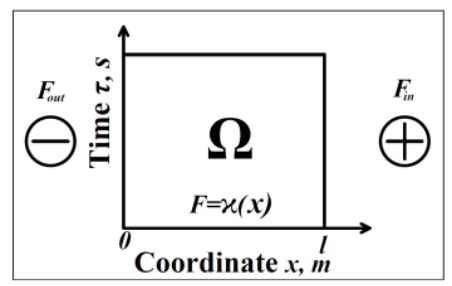

Fig. 1. Spatial-time domain of the enclosing structure.

Let's use third-kind boundary conditions to take into account moisture transfer between air and the enclosing structure.

Let's represent third-kind boundary condition for an enclosing structure surface, which contacts with outside air, as follows:

$$
-\left.\mu \frac{\partial F}{\partial x}\right|_{x=0}=\beta_{e x t}\left(F_{e x t}-F_{1}\right) .
$$

where $F_{\text {ext }}$ - outside air moisture potential corresponding to partial pressure of outside air water vapor, $\mathrm{Pa} ; F_{1}$ - moisture potential of the enclosing structure section which contacts with outside air, $\mathrm{Pa} ; \beta_{\text {ext }}$ - moisture exchange coefficient of outside air and enclosing structure surface, $\mathrm{kg} /\left(\mathrm{m}^{2} \cdot \mathrm{s} \cdot \mathrm{Pa}\right)$.

Let's represent third-kind boundary condition for an enclosing structure surface, which contacts with inside air, as follows:

$$
\left.\mu \frac{\partial F}{\partial x}\right|_{x=l}=\beta_{i n}\left(F_{i n}-F_{N}\right) .
$$

where $F_{\text {in }}$ - inside air moisture potential corresponding to partial pressure of inside air water vapor, $\mathrm{Pa} ; \mathrm{F}_{N}$ - moisture potential of the enclosing structure section which contacts with inside air, $\mathrm{Pa} ; \beta_{\text {in }}$ - moisture exchange coefficient of inside air and enclosing structure surface, $\mathrm{kg} /\left(\mathrm{m}^{2} \cdot \mathrm{s} \cdot \mathrm{Pa}\right)$.

Let's consider discrete-continuous $[18,19]$ approximation of spatial-time domain $\Omega$ [fig. 2]. 


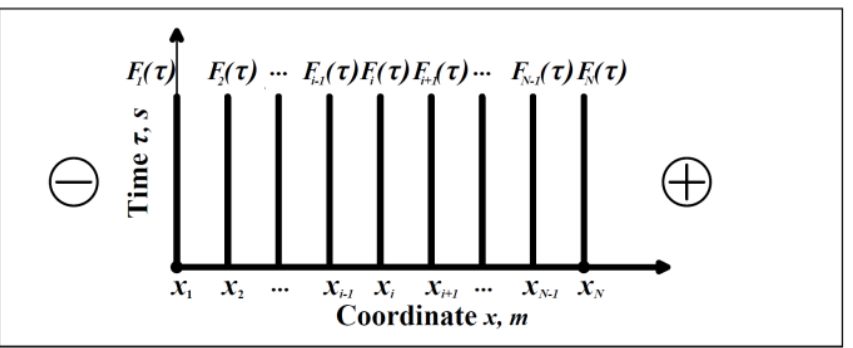

Fig. 2. Discrete-continuous approximation of spatial-time domain taking into account third-kind boundary conditions at enclosing structure boundaries.

In this case equations (7), (9) and (10) are equivalent to simultaneous equations:

$$
\left\{\begin{array}{l}
\frac{\partial F_{1}}{\partial \tau}=\frac{\kappa}{h^{2}} \cdot E_{t 1} \cdot\left(-\left(1+\frac{\beta_{e x t}}{\mu} \cdot h\right) \cdot F_{1}+F_{2}\right)+\frac{\kappa}{h^{2}} \cdot E_{t 1} \cdot \frac{\beta_{e x t}}{\mu} \cdot h \cdot F_{e x t} \\
\frac{\partial F_{i}}{\partial \tau}=\frac{\kappa}{h^{2}} \cdot E_{t i} \cdot\left(F_{i-1}-2 \cdot F_{i}+F_{i+1}\right), i=2,3,4, \ldots, N-1 \\
\frac{\partial F_{N}}{\partial \tau}=\frac{\kappa}{h^{2}} \cdot E_{t N} \cdot\left(F_{N-1}-\left(1+\frac{\beta_{i n}}{\mu} \cdot h\right) F_{N}\right)+\frac{\kappa}{h^{2}} \cdot E_{t N} \cdot \frac{\beta_{i n}}{\mu} \cdot h \cdot F_{i n} \\
F(x, 0)=\chi(x), 0 \leq x \leq l
\end{array} .\right.
$$

where $h$ - enclosing structure partition step in coordinate $x ; i$ - enclosing structure section number; $\chi$ - initial moisture potential distribution, $\mathrm{Pa}$.

Assuming that inside air moisture potential is constant, let's represent moisture potential variation $F_{\text {out }}$ outside construction during the month as a linear function:

$$
F_{\text {ext }}=m \cdot \tau+n \text {. }
$$

where $m$ - boundary conditions slope ratio within a month; $n$ - boundary conditions graph rise within a month [Fig.1], Pa;

Equations (11) taking into account (12) represent a Cauchy problem, and are written as the following in matrix form:

$$
\left\{\begin{array}{l}
\bar{F}_{\tau}^{\prime}=E_{t} \cdot A \cdot \bar{F}+p \cdot \tau \cdot \bar{L}+\bar{B} \\
\bar{F}(0)=\bar{\chi}, 0 \leq x \leq l
\end{array} .\right.
$$

where $p=\kappa \cdot E_{t 1} \cdot \beta_{\text {ext }} \cdot h \cdot m /\left(h^{2} \cdot \mu\right)$.

$$
A=\frac{\kappa}{h^{2}} \cdot\left(\begin{array}{ccccc}
-\left(1+\beta_{\text {ext }} \cdot h / \mu\right) & 1 & 0 & 0 & 0 \\
1 & -2 & 1 & 0 & 0 \\
0 & \ddots & \ddots & \ddots & 0 \\
0 & 0 & 1 & -2 & 1 \\
0 & 0 & 0 & 1 & -\left(1+\beta_{i n} \cdot h / \mu\right)
\end{array}\right) \cdot E_{t}=\left(\begin{array}{ccccc}
E_{t 1} & 0 & 0 & 0 & 0 \\
0 & E_{t 2} & 0 & 0 & 0 \\
\ldots & \ldots & \ldots & \ldots & \ldots \\
0 & 0 & 0 & E_{t(N-1)} & 0 \\
0 & 0 & 0 & 0 & E_{t N}
\end{array}\right) .
$$




$$
\bar{F}_{\tau}^{\prime}=\left(\begin{array}{c}
F_{1}^{\prime}(\tau) \\
F_{2}^{\prime}(\tau) \\
\ldots \\
F_{N-1}^{\prime}(\tau) \\
F_{N}^{\prime}(\tau)
\end{array}\right) . \bar{F}=\left(\begin{array}{c}
F_{1} \\
F_{2} \\
\ldots \\
F_{N-1} \\
F_{N}
\end{array}\right) . \bar{L}=\left(\begin{array}{c}
1 \\
0 \\
\ldots \\
0 \\
0
\end{array}\right) . \bar{B}=\left(\begin{array}{c}
\kappa \cdot E_{t 1} \cdot \beta_{\text {ext }} \cdot h \cdot n /\left(h^{2} \cdot \mu\right) \\
0 \\
\ldots \\
0 \\
\kappa \cdot E_{t N} \cdot \beta_{i n} \cdot h \cdot F_{i n} /\left(h^{2} \cdot \mu\right)
\end{array}\right) .
$$

Problem (13) solution can be written as:

$$
\begin{array}{r}
\bar{F}=p \cdot\left(\left(E_{t} \cdot A\right)^{-2} \cdot e^{E_{t} \cdot A \cdot \tau}-\tau \cdot\left(E_{t} \cdot A\right)^{-1}-\left(E_{t} \cdot A\right)^{-2}\right) \cdot \bar{L}+ \\
+\left(E_{t} \cdot A\right)^{-1}\left(e^{E_{t} \cdot A \cdot \tau}-E\right) \cdot \bar{B}+e^{E_{t} \cdot A \cdot \tau} \cdot \bar{F}_{0} .
\end{array}
$$

The expression (14) presumes that enclosing structure moisture potential is calculated separately per every month.

\section{Results and discussion}

Calculation results based on the solution (14) have been compared with results according to unsteady-state method [17] and engineering method [17]. The method [17] has been realized by finite difference method using an explicit difference scheme. Initial data for calculation: single-layer enclosing structure made of $0,6 \mathrm{~m}$ thick aerated concrete. Inside air temperature $22^{\circ} \mathrm{C}$ and relative air humidity $60 \%$ have been maintained constant in the building. Construction area: Moscow. Comparison of moisture behavior calculation results obtained by three different methods of moisture potential theory for January is given at [fig. 3].

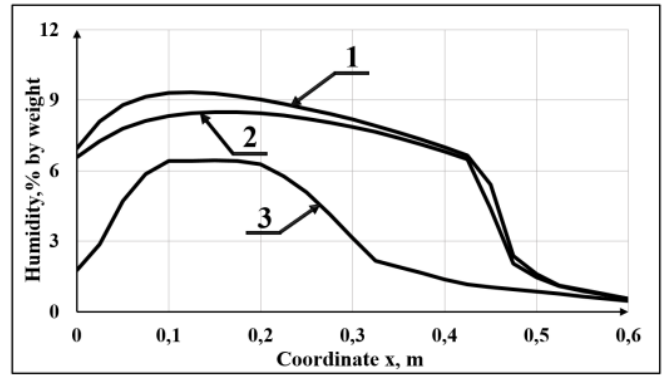

Fig. 3. Comparison of moisture potential theory methods for moisture regime calculation of singlelayer enclosing structure in January $(1$ - moisture distribution in enclosing structure according to Gagarin's unsteady-state method, 2 - moisture distribution in enclosing structure according to discrete-continuous method, 3 - moisture distribution in enclosing structure according to Kozlov's engineering method).

The figure shows that moisture distribution obtained by proposed discrete-continuous method gives quantitative and qualitative results similar to unsteady-state method results [17]. Average moisture value disagreement in enclosing structure thickness does not exceed $7 \%$ for method [17] and the proposed method.

\section{Conclusions}

The proposed improved unsteady-state discrete-continuous mathematical model allows material moisture determination in any enclosing structure section at any moment of time. Moisture transfer between enclosing structure surfaces and air is determined by third-kind 
boundary conditions. Maximum water vapor tension allows taking into account temperature distribution influence on the enclosing structure. Calculation results of the proposed model agree completely with solution obtained in number by means of unsteady-state model [17]. However discrete-continuous distribution is an analytical expression, which makes calculation considerably easier, and which can be used by design engineers in practice for unsteady-state moisture behavior investigation.

\section{References}

1. A. Hoseini, A. Bahrami, Journal of building engineering, 13, 107-115 (2017)

2. HQ. Jin, XL. Yao, LW. Fan, X. Xu, ZT., International journal of heat and mass transfer, 92, 589-602 (2017)

3. D. Belkharchouche, A. Chaker, International journal of hydrogen energy, 41, 71197125. (2016)

4. Z. Suchorab, D. Barnat-Hunek, H. Sobczuk, Journal of building engineering, 18, 111120 (2011)

5. Z. Wu, HS. Wong, NR Buenfeld, Cement and concrete research, 98, 136-154 (2017)

6. E. Zvicevicius, A. Raila, A. Cipliene, Z. Cerniauskiene, Z. Kadziuliene, V. Tilvikiene, 119, 185-192 (2018)

7. F. Georget, J. H. Prevost, B. Huet, Cement and concrete research, 104, 1-12 (2018)

8. ZC. Liu, W. Hansen, FZ. Wang, Construction and building materials, 158, 181-188 (2018)

9. B. Vavrovic, Advanced Materials Research, 855, 97-101 (2014)

10. S. Lal, F. Lucci, T. Defraeye, L.D. Poulikakos, M.N. Partl, D. Derome, J. Carmeliet, International journal of thermal sciences, 123, 86-98. (2018)

11. Y.C. Tang; J.C. Min, X.M. Wu, International journal of heat and mass transfer, 116, 371-376 (2018)

12. L. Skerget, A. Tadeu, J. Ravnik, Engineering analysis with boundary elements, 74, 2433 (2017)

13. J.A. Eklund, H. Zhang, H.A. Viles, T. Curteis, International journal of architectural heritage, 7, 207-224 (2013)

14. O. Sass, H.A. Viles, Limestone in the built environment: present day challenges for the preservation of the past, 331, 237-249 (2010)

15. A.S. Petrov, V.N. Kupriyanov, International journal of pharmacy and technology, 8, 11248-11256. (2016)

16. P. Perre, F. Pierre, J. Casalinho, M. Ayouz, Drying technology, 33, 1068-1075 (2015)

17. V.G. Gagarin, V.V. Kozlov, K.P. Zubarev, Housing Construction, 6, 8-12 (2016) (rus)

18. V.N. Sidorov, S.M. Matskevich, Procedia Engineering, 111, 726-733 (2015)

19. V.N. Sidorov, S.M. Matskevich, Key Engineering Materials, 685, 211-216 (2016) 